\title{
ESTIMASI NILAI PEMULIAAN DAN MPPA (Most Probable Producing Ability) KUDA PACU BERDASARKAN SIFAT KECEPATAN LARI
}

\author{
Muh. M. Suryana, B.J. Takaendengan*, U. Paputungan, E. Pudjihastuti
}

Fakultas Peternakan Universitas Sam Ratulangi, Manado 95115

\begin{abstract}
ABSTRAK
Penelitian ini bertujuan untuk mendapatkan angka pendugaan nilai pemuliaan dari masing masing induk/ pejantan kuda pacu yang dipelihara di Minahasa sebagai dasar seleksi kuda pacu berdasarkan keunggulan genetik sifat kecepatan.Penelitian ini pertama menggunakan analisis deskriptif berupa analisis rataan, standar defisiasi, dan koefisien keragaman untuk melihat gambaran umum kecepatan dan performa lari kuda pacuan. Kemudian data kecepatan kuda pacu dihitung nilai heritabilitas dan ripitabilitas untuk menduga nilai pemuliaan probability breeding value (PBV). Hasil dari penelitian ini menunjukkan bahwa nilai heritabilitas dan ripitabilitas yang diperoleh bervariasi dari rendah sampai tinggi. Hasil Pendugaan Breeding Value (PBV) tertinggi $=0,08691$ (pejantan H). Sedangkan untuk nilai MPPA (Most Probable Producing Ability) tertinggi dalam populasi $=0,1845$ (individu B010) dimana rataan nilai MPPA seluruh populasi sebesar $=0,0239$. Kesimpulan dari penelitian ini menempatkan kuda pacu atas nama "Swift Jhon" dan "Super Princes" sebagai pejantan dan individu yang memiliki pertambahan rata-rata sifat kecepatan lari tertinggi dimiliki oleh individu atas nama "Super Princes".
\end{abstract}

Kata kunci :Kuda pacu, kecepatan lari, EBV, MPPA

\footnotetext{
*Korespondensi (corresponding author):

Email : juvarda@unsrat.ac.id
}

\section{ABSTRACT}

\begin{abstract}
ESTIMATION BREEDING VALUE AND MPPA (Most Probable Producing Ability) OF RACEHORSES BASED ON NATURE OF RUNNING SPEED. The aim of this study was to obtain the estimated number of breeding values from the racehorses parent in Minahasa for racehorse selection based on the superiority of genetic traits of speed. The descriptive analysis such asaverage, standard deviation and coefficient of variation of the speed and performance were done as the first step. Heritability, ripitability and the probability of breeding value (PBV) were calculated after all. The results of this study indicate that the value of heritability and repeatability obtained varies from low to high. The highest estimation of breeding value (PBV) for male $(\mathrm{H})$, the highest MPPA (Most Probable Producing Ability) value in the population (individual B010) and the average MPPA value for the entire population were $0.0869,0.1845$ and 0.0239 respectively. The conclusion of this study puts the racehorse with the name "Swift Jhon" and "Super Princes" as males and individuals who have an average increase in the nature of the highest running speed.
\end{abstract}

Keywords: Racehorse, Speed, EBV, MPPA 


\section{PENDAHULUAN}

Kuda pacu yang bermutu tinggi memiliki nilai ekonomi tersendiri dan merupakan kebanggaan tersendiri bagi pemiliknya, karena selain keuntungan dalam hal kepuasan pribadi juga dapat memberikan keuntungan nyata dalam bentuk perolehan hadiah pada prestasi yang berhasil diraih oleh kuda pacu tersebut. Kuda pacu Indonesia merupakan kuda hasil grading-up kuda lokal sumba dengan kuda pacu unggul thoroughbred yang membentuk "bangsa baru" yang telah beradaptasi baik dengan lingkungan Indonesia sehingga dianggap sebagai kuda lokal (Ambo, 2014). Kuda silangan jantan Thoroughbred Australia dengan betina poni lokal, menghasilkan kuda pacu lokal. Istilah kuda pacu lokal, dikenal dengan istilah G1 untuk keturunan pertama, kedua (G2), dan seterusnya memiliki postur badan yang besar. Persilangan ini menjadi syarat utama mengikuti pacuan kuda klasik yang diselenggarakan di Indonesia. Kuda pacu, salah satu jenis ternak yang perlu mendapat perhatian khusus karena merupakan sumber daya yang sangat strategis untuk dikembangkan (Oroh et al., 2004).

Performa kecepatan kuda pacu menurut Tolley et al. (1983), adalah dengan melihat kecepatan kuda pada jarak lari yang ditempuh. Oleh sebab itu catatan perlombaan pacuan kuda dapat dimanfaatkan sebagai salah satu cara yang terbaik untuk menyeleksi pejantan/indukan kuda yang unggul, sehingga diharapkan kualitas bibit kuda pacu dan mutu genetik kuda lokal bisa lebih ditingkatkan (Langlois, 2007).

Metode seleksi merupakan upaya pemuliaan untuk meningkatkan sifat kecepatan lari kuda pacu Indonesia, sehingga karakteristik kecepatan lari kuda pacu Indonesia khususnya kuda pacu Minahasa dapat ditingkatkan. Masalahnya di Minahasa sampai saat ini peternak kuda pacu belum melakukan upaya pemuliaan yang didasarkan pada hasil kajian ilmiah yang benar. Berdasarkan permasalahan itulah penulis ingin melakukan penelitian guna memperoleh informasi mengenai potensi keunggulan fenotipik dan genetik kuda pacu di Minahasa berdasarkan sifat kecepatan lari kuda yang bersumber dari kumpulan hasil perlombaan pacuan kuda yang diselenggarakan oleh Persatuan Olahraga Berkuda (PORDASI) Sulawesi Utara.

Penelitian ini bertujuan untuk mendapatkan angka pendugaan nilai pemuliaan dari masing masing induk/ pejantan kuda pacu yang dipelihara di Minahasa sebagai dasar upaya seleksi kuda pacu berdasarkan keunggulan genetik sifat kecepatan lari. Diharapkan dari pejantan/ induk yang terseleksi diperoleh bibit kuda pacu unggul di Minahasa. 


\section{MATERI DAN METODE PENELITIAN}

\section{Materi Penelitian}

Materi penelitian merupakan sumber data yang diperoleh dari berbagai even kejuaraan pacuan kuda yang dilaksanakan di Provinsi Sulawesi Utara, Indonesia sejak tahun 1998-2018. Data-data tersebut berupa data sekunder (Takaendengan et al., 2011) dan data hasil wawancara dengan berbagai pihak yang terlibat pada kejuaraan yang dilaksanakan. Data yang dikumpulkan terdiri darinama kuda, nama induk dan pejantan, nama pemilik kuda, nama event, waktu tempuh, jarak lintasan lomba, dan selisih jarak dengan kuda peserta yang finish sebelumnya. Kesemuanya kuda yang dicatat berasal dari Minahasa (Sulawesi Utara).

\section{Metode Penelitian}

Awalnya data dihimpun dari berbagai sumber data. Data terkumpul diseleksi untuk mendapatkan data kuda pacu yang berasal dari Minahasa. Data-data tersebut dianalisa menggunakan analisis deskriptif dengan menghitung rataan, standar defisiasi, dan koefisien keragaman. Hal ini dilakukan untuk melihat gambaran umum kecepatan dan performa lari kuda pacuan. Kemudian data kecepatan kuda pacu dihitung nilai heritabilitas dan ripitabilitas untuk menduga nilai pemuliaan probability breeding value (PBV). Tabulasi dan perhitngan menggunakan Excell Microsoft Office 2007. Untuk pendugaan nilai ripitabilitas dalam penelitian ini, data(sampel) yang digunakan adalah data anak kuda (individu) yang memiliki catatan waktu finish 5-6 kali. Penyeragaman jumlah sampel ini bertujuan untuk menghindari terdapatnya perbedaan nilai $k$ (koefisien dengan jumlah anak yang berbeda per pejantan) yang signifikan sehingga menyebabkan hasil perbandingan nilai antara individu (saudara tiri sebapak) tidak relevan (Becker, 1968).

$$
h_{s}^{2}=\frac{4 \sigma_{s}^{2}}{\sigma_{s}^{2}+\sigma_{w}^{2}}
$$

Keterangan:

$$
\sigma_{w}^{2}=\mathrm{MSw} \text { dan } \sigma_{s}^{2}=\frac{M S \mathrm{~s}-\mathrm{MSw}}{K}
$$

$$
\begin{aligned}
h_{s}^{2}= & \text { Nilai heritabilitas dari } \\
& \text { pejantan } \\
\sigma_{w}^{2}= & \text { Ragam antar individu dalam } \\
& \text { kelompok anak } \\
\sigma_{S}^{2}= & \text { Ragam antar rata-rata } \\
& \text { kelompok anak dan pejantan } \\
M S_{W}= & \text { Kuadrat tengah anak } \\
M S_{\mathrm{S}}= & \text { Kuadrat tengah pejantan }
\end{aligned}
$$

Dimana,

$$
\mathrm{k}=\frac{1}{s-1}\left(n-\frac{\sum n_{i}^{2}}{n}\right)
$$

Keterangan :

$$
\begin{aligned}
& \mathrm{k}=\text { Koefisien dengan jumlah } \\
& n=\text { Jumlah anak total } \\
& n_{i} \quad=\text { Jumlah anak per pejantan } \\
& \mathrm{s}=\text { Banyak pejantan }
\end{aligned}
$$

$$
R=\frac{\sigma_{w}^{2}}{\sigma_{w}^{2}+\sigma_{e}^{2}}
$$




$$
\sigma_{e}^{2}=\mathrm{MSe} \text { dan } \sigma_{w}^{2}=\frac{M S \mathrm{w}-\mathrm{MSe}}{K 1}
$$

Keterangan :

$$
\begin{aligned}
& \mathrm{R} \quad=\text { Ripitabilitas } \\
& \sigma^{2} w=\text { Ragam kecepatan pacu antara }
\end{aligned}
$$

Menurut Ardika et al. (2015) secara umum pendugaan nilai pemuliaan atau PBV untuk sifat kuantitatif menggunakan formula:

$$
P B V=\mathrm{P}+\mathrm{b} 1(\mathrm{Pi}-\mathrm{P})
$$

Keterangan :

$$
\begin{aligned}
\mathrm{PBV}= & \text { Probable breeding value } \\
\mathrm{b} 1= & \text { Koefisien regresi genotype } \\
& \text { individu dengan fenotipenya } \\
\mathrm{P}= & \text { Rataan fenotipe individu } \\
& \text { contemporary } \\
\mathrm{Pi}= & \begin{array}{l}
\text { Nilai fenotipe individu } \\
\text { terseleksi }
\end{array}
\end{aligned}
$$

Untuk mendapatkan rataan populasi dan rataan individu dengan menggunakan Most Probable Producing Ability (MPPA) menurut Warwick et al. (1987):

$$
\mathrm{MPPA}=\frac{n r}{1+(n-1) r}(\bar{P} \mathrm{x}-\bar{P} o)
$$

Keterangan :

$$
\begin{aligned}
\bar{P} o= & \text { probable breeding value } \\
\bar{P} x= & \text { koefisien regresi genotype } \\
& \text { individu dengan fenotipenya } \\
\mathrm{N}= & \begin{array}{l}
\text { Rataan fenotipe individu } \\
\text { contemporary }
\end{array}
\end{aligned}
$$

$$
\mathrm{R}=\operatorname{lilai}_{\text {terseleksi }} \text { fenotipe individu }
$$

\section{HASIL DAN PEMBAHASAN}

\section{Rataan, Standar Deviasi dan Koefisien Variasi Kecepatan Lari Kuda Pacu di Minahasa.}

Berdasarkan hasil yang tertera pada Tabel 1 terlihat bahwa kecepatan rata-rata berkisar antara $14,62 \pm 0,79 \mathrm{~m} /$ detik sampai dengan $15,45 \pm 1,34 \mathrm{~m} /$ detik atau $\pm 52 \mathrm{~km} / \mathrm{jam}$ sampai dengan $\pm 55 \mathrm{~km} / \mathrm{jam}$. Kecepatan tertinggi dari kuda pacu yang di ukur adalah 23,21 $\mathrm{m} /$ detik dan kecepatan terendah adalah 9,35 m/detik dengan kecepatan ratarata dari seluruh populasi kuda yang dipacu adalah $15,13 \pm 0,80 \mathrm{~m} /$ detik.

Hasil rata-rata kecepatan populasi kuda pacu (Tabel 1) lebih tinggi jika dibandingkan dengan rata-rata kecepatan dari kuda pacu Arab murni yang ada di Belanda yaitu 13,80 m/detik (Schurink et al., 2009) dan kuda pacu Arab Thoroughbred yang ada di Bulgaria yaitu 12,90 m/detik (Sabeva, 2000). Namun, hasil ini lebih rendah jika dibandingkan dengan rata-rata kecepatan kuda pacu Thoroughbred Turki yaitu $15,30 \mathrm{~m} /$ detik (Ekiz dan Koçak, 2007) dan rata-rata kecepatan kuda quarter Brazil yaitu 17,10 m/detik (Corrêa dan Mota, 2007). Adanya perbedaan hasil rata-rata kecepatan antara 
Tabel 1.Nilai Rataan, Standar Deviasi, dan Koevisien VariasiSifat Kecepatan Kuda Pacu Pejantan di Minahasa.

\begin{tabular}{ccccc}
\hline Pejantan & $\begin{array}{c}\text { Rataan Kecepatan Jenis Kuda } \\
(\mathrm{m} / \text { detik }) \pm \text { SD }\end{array}$ & $\begin{array}{c}\text { Max } \\
(\mathrm{m} / \text { detik })\end{array}$ & $\begin{array}{c}\text { Min } \\
(\mathrm{m} / \mathrm{detik})\end{array}$ & $\begin{array}{c}\text { C.V } \\
(\%)\end{array}$ \\
\hline A & $15,09 \pm 0,75$ & 19,89 & 9,35 & 4,98 \\
B & $14,62 \pm 0,79$ & 18,22 & 13,23 & 5,39 \\
C & $15,14 \pm 0,63$ & 16,31 & 10,43 & 4,15 \\
D & $15,37 \pm 0,62$ & 16,99 & 13,97 & 4,01 \\
E & $15,12 \pm 1,25$ & 16,64 & 9,75 & 8,27 \\
F & $15,02 \pm 0,50$ & 16,33 & 14,22 & 3,30 \\
G & $15,13 \pm 0,35$ & 15,88 & 14,41 & 2,34 \\
H & $15,45 \pm 1,34$ & 23,21 & 11,31 & 8,67 \\
I & $14,90 \pm 0,55$ & 16,33 & 12,90 & 3,71 \\
J & $15,30 \pm 0,56$ & 16,92 & 14,00 & 3,68 \\
K & $15,07 \pm 1,13$ & 16,77 & 11,33 & 7,53 \\
L & $15,15 \pm 0,86$ & 16,32 & 11,36 & 5,68 \\
M & $15,25 \pm 0,53$ & 16,66 & 14,12 & 3,49 \\
N & $15,22 \pm 1,55$ & 16,14 & 9,60 & 10,18 \\
\hline Rataan & $15,13 \pm 0.80$ & 23,21 & 9,35 & 5,29 \\
\hline
\end{tabular}

Keterangan : Pejantan A=Manguni Makasiaow ; $\mathrm{B}=$ Century Time ; $\mathrm{C}=$ Putra Bunaken ; $\mathrm{D}=$ Sabeil Esa Tama ; $\mathrm{E}=$ Decibel II ; F=Champ ; G=Putra Pinabentengan ; H=Swift John ; I=Bunaken ; J=Decibel ; K=Lord Lichen ; $\mathrm{L}=$ Imaginero ; $\mathrm{M}=$ Soputan Tulen ; N=Juragan Tanjungsari.

kuda pacu diatas mungkin disebabkan oleh beberapa faktor seperti jenis kuda yang berbeda di setiap negara, jenis lintasan/perlombaan (Bowling dan Ruvinsky, 2000), atau iklim di Negara tersebut (Butram et al, 1998). Penelitian ini juga menunjukkan bahwa terdapat keragaman yang tinggi terhadap sifat kecepatan lari kuda berkisar antara 2,34\% sampai dengan $10,18 \%$. Tingginya keragaman pada populasi ini bisa dimanfaatkan untuk dilakukannya seleksi demi mendapatkan pejantan/ turunan yang memiliki kualitas genetik yang unggul berdasarkan sifat kecepatan lari (Makalalag et al., 2014).

\section{Analisis Nilai Heritabilitas dan PBV Pejantan}

Untuk pendugaan nilai heretabilitas berdasarkan hasil penelitian ini didapatkan pejantan $\mathrm{B}$ memiliki nilai heritabilitas terendah $\left(\mathrm{h}^{2}=0,07\right)$ dan pejantan $\mathrm{N}$ memiliki nilai heritabilitas tertinggi $\left(\mathrm{h}^{2}=\right.$ 0,48). Sedangkan untuk pengklasifikasian nilai heritabilitas pejantan menurut petunjuk Sulastri dan Hamdani (2013) adalah pejantan A, B, C, dan D termasuk dalam 
klasifikasi rendah $(0,0-0,1)$, pejantan E, F, G, H, I, J, dan L termasuk dalam klasifikasi sedang $(0,1-0,3)$, pejantan $\mathrm{K}, \mathrm{M}$, dan $\mathrm{N}$ termasuk dalam klasifikasi tinggi $(0,3-1,0)$. Sedangkan untuk pendugaan nilai pemuliaan (NP) / estimated breeding value (EBV) berdasarkan Tabel 2 adalah pejantan $\mathrm{H}$ merupakan kuda yang memiliki nilai EBV tertinggi $(0,08691)$ meskipun memiliki nilai heritabilitas $\left(\mathrm{h}^{2}\right)$ yang tergolong sedang $(0,21)$. Sedangkan pejantan $K$ hanya masuk urutan ke-9 (0,01115) dengan nilai heritabilitas $\left(\mathrm{h}^{2}\right)$ yang tergolong tinggi $(0,34)$. Hal tersebut wajar karena menurut Sulastri dan Hamdani (2013) nilai heritabilitas bukan merupakan nilai mutlak namun merupakan hasil pendugaan potensi genetik suatu sifat dalam populasi yang diestimasi atau diduga berdasarkan sifat luar yang dapat diukur (sifat kuantitatif).

Oleh karena itu, diperlukan penentuan EBV untuk melakukan penilaian yang berdasar pada mutu genetik ternak untuk suatu sifat tertentu yang diberikan secara relatif atas kedudukannya didalam populasi (Hardjosubroto, 1994). Estimasi nilai heritabilitas $\left(\mathrm{h}^{2}\right)$ pejantan yang telah diranking berdasarkan nilai pemuliaan (BV) dapat dilihat pada Tabel 2.

Tabel 2. Nilai Heretabilitas dan EBV Pejantan

\begin{tabular}{ccccc}
\hline Pejantan & $\mathrm{h}^{2}$ & $\mathrm{~S} . \mathrm{E}\left(\mathrm{h}^{2}\right)$ & $\mathrm{PBV}$ & Ranking \\
\hline A & 0,05 & 0,22 & 0,00247 & 11 \\
B & 0,07 & 0,26 & $-0,03025$ & 14 \\
C & 0,08 & 0,32 & 0,00751 & 10 \\
D & 0,07 & 0,31 & 0,02218 & 7 \\
E & 0,14 & 0,45 & 0,01158 & 8 \\
F & 0,19 & 0,53 & $-0,00343$ & 12 \\
G & 0,25 & 0,57 & 0,02346 & 6 \\
H & 0,21 & 0,56 & 0,08691 & 1 \\
I & 0,20 & 0,62 & $-0,02885$ & 13 \\
J & 0,22 & 0,64 & 0,05692 & 4 \\
K & 0,34 & 0,79 & 0,01115 & 9 \\
L & 0,29 & 0,78 & 0,03250 & 5 \\
M & 0,35 & 0,71 & 0,07535 & 3 \\
N & 0,48 & 0,82 & 0,08389 & 2 \\
\hline
\end{tabular}

Keterangan : Pejantan A=Manguni Makasiaow ; $\mathrm{B}=$ Century Time ; $\mathrm{C}=$ Putra Bunaken ; D=Sabeil Esa Tama ; E=Decibel II ; F=Champ ; G=Putra Pinabentengan ; H=Swift John ; I=Bunaken ; J=Decibel ; K=Lord Lichen ; L=Imaginero ; M=Soputan Tulen ; N=Juragan Tanjungsari 


\section{Nilai Ripitabilitas dan MPPA Individu}

Untuk pendugaan nilai ripitabilitas berdasarkan hasil penelitian ini didapatkan pejantan $\mathrm{N}$ memiliki nilai ripitabilitas terendah $(\mathrm{R}=0,1476)$ dan pejantan $\mathrm{J}$ memiliki nilai ripitabilitas tertinggi $(\mathrm{R}=$ 0,6914). Sedangkan untuk pengklasifikasian nilai ripitabilitas pejantan menurut petunjuk Sulastri dan Hamdani (2013) adalah pejantan $\mathrm{A}, \mathrm{B}, \mathrm{F}$ dan $\mathrm{N}$ termasuk dalam klasifikasi rendah $(0,0-0,2)$ pejantan $\mathrm{H}$ termasuk dalam klasifikasi sedang (0,2 0,4), pejantan $\mathrm{C}$, I, dan $\mathrm{J}$ termasuk dalam klasifikasi tinggi $(0,4-1,0)$ seperti yang tertera pada Tabel 3.

Nilai MPPA (Most Probable producingProducing Ability) pada individu B010 dari hasil analisis menunujukkan

Tabel 3. Nilai Ripitabilitas dan MPPAIndividu

\begin{tabular}{cccccccc}
\hline Individu & $\begin{array}{c}\text { AVG } \\
\text { Individu } \\
\text { (m/detik) }\end{array}$ & Pejantan & $\begin{array}{c}\text { AVG } \\
\text { Pejantan } \\
\text { (m/detik) }\end{array}$ & R & $\begin{array}{c}\text { S.E } \\
(\text { R. })\end{array}$ & $\begin{array}{c}\text { MPPA } \\
(\mathrm{m} / \text { detik })\end{array}$ & Rank \\
\hline B010 & 15,80 & B & 14,62 & 0,1561 & 0,1251 & 0,1845 & 1 \\
C007 & 15,52 & C & 15,14 & 0,4172 & 0,2008 & 0,1574 & 2 \\
J001 & 15,48 & J & 15,30 & 0,6914 & 0,3675 & 0,1262 & 3 \\
B013 & 15,42 & B & 14,62 & 0,1561 & 0,1251 & 0,1248 & 4 \\
A009 & 15,73 & A & 15,09 & 0,1880 & 0,1125 & 0,1201 & 5 \\
B006 & 15,35 & B & 14,62 & 0,1561 & 0,1251 & 0,1150 & 6 \\
B007 & 15,33 & B & 14,62 & 0,1561 & 0,1251 & 0,1113 & 7 \\
B011 & 15,30 & B & 14,62 & 0,1561 & 0,1251 & 0,1063 & 8 \\
C003 & 15,39 & C & 15,14 & 0,4172 & 0,2008 & 0,1060 & 9 \\
C004 & 15,38 & C & 15,14 & 0,4172 & 0,2008 & 0,1016 & 10 \\
C001 & 15,37 & C & 15,14 & 0,4172 & 0,2008 & 0,0973 & 11 \\
B008 & 15,24 & B & 14,62 & 0,1561 & 0,1251 & 0,0965 & 12 \\
B002 & 15,18 & B & 14,62 & 0,1561 & 0,1251 & 0,0877 & 13 \\
A007 & 15,51 & A & 15,09 & 0,1880 & 0,1125 & 0,0792 & 14 \\
H003 & 15,67 & H & 15,45 & 0,3538 & 0,2849 & 0,0787 & 15 \\
N001 & 15,74 & N & 15,22 & 0,1476 & 0,3032 & 0,0780 & 16 \\
F001 & 15,41 & F & 15,02 & 0,1877 & 0,2596 & 0,0736 & 17 \\
B003 & 15,08 & B & 14,62 & 0,1561 & 0,1251 & 0,0720 & 18 \\
A003 & 15,46 & A & 15,09 & 0,1880 & 0,1125 & 0,0686 & 19 \\
N002 & 15,66 & N & 15,22 & 0,1476 & 0,3032 & 0,0652 & 20 \\
I002 & 15,05 & I & 14,90 & 0,4244 & 0,3472 & 0,0651 & 21 \\
H002 & 15,63 & H & 15,45 & 0,3538 & 0,2849 & 0,0649 & 22 \\
$\ldots$ & $\ldots$ & $\ldots$ & $\ldots$ & $\ldots$ & $\ldots$ & $\ldots$ & $\ldots$ \\
F002 & 14,69 & F & 15,02 & 0,1877 & 0,2596 & $-0,0627$ & 74 \\
\hline
\end{tabular}

Keterangan:Individu B010=Super Princes ; C007=Gentelement Esah ; J001=Blessing Star ; B013=Siouw kurur ; A009=Noni Toraget ; B006=Maesa Queen ; B007=Maesa Star ; B011=Toroani ; C003=Perkasa MM ; C004=Putra MM ; C001=Bunga Kasih ; B008=Minsel Queen ; B002=Beringin KK ; A007=Maesa Putra ; H003=Prince Alzao ; N001=Anglia ; F001=Ratu Pinasiowan ; B003=Brutus MM ; A003=Bunga Bangsa ; N002=Biruang Hitam ; I002=Putri Sanubari ; H002=Cinto Nagari ; F002=Red Princes. 
bahwa kuda ini memiliki nilai MPPA tertinggi dari seluruh populasi yang merupakan anak keturunan dari pejantan B yaitu $0,1845 \mathrm{~m} /$ detik. Ini menunjukkan bahwa kuda B010 yang merupakan anak keturunan dari pejantan B memiliki estimasi nilai pertambahan rata-rata kecepatan lari sebesar $0,1845 \mathrm{~m} /$ detik yang berasal dari sifat kecepatan lari yang diturunkan dari pejantan B. Oleh sebab itu, berdasarkan hasil MPPA individu diatas diharapkan kuda pacu generasi berikutnya akan mempunyai pertambahan kecepatan sesuai dengan nilai MPPA-nya. Meskipun hal tersebut tidak mutlak karena mungkin saja nilai MPPA tersebut dipengaruhi juga oleh nilai ripitabilitas dari gen betina/induk dari kuda (Astuti et al., 2011).

\section{KESIMPULAN}

Kuda atas nama "Swift Jhon" merupakan pejantan yang memiliki estimasi nilai pertambahan rata-rata sifat kecepatan terbaik diantara semua pejantan. Sedangkan untuk nilai MPPA (Most Probable Producing Ability) tertinggi dalam populasi yang memiliki pertambahan rata-rata sifat kecepatan lari dimiliki oleh individu atas nama "Super Princes"

\section{SARAN}

Penelitian lanjutan dengan jumlah sampel yang lebih banyak perlu dilakukan sehingga menambah jumlah keragaman guna mendapatkan hasil yang lebih optimal. Untuk para peternak dapat memilih pejantan yang sesuai dengan kemampuan dana masing-masing berdasarkan dengan hasil penelitian.

\section{DAFTAR PUSTAKA}

Ambo S.F., S. Adiani, U Paputungan, dan J. Paat. 2014 Ripitabilitas kecepatan lari dan tinggi pundak anak kuda pacu umur berbeda pada keturunan pejantan "Manguni Makasiow" dengan metode korelasi dalam klas. J. Zootek 34(2): 71-81.

Astuti, V.D., R.R. Noor, dan B.J. Takaendengan 2011. Ripitabilitas Sifat Kemampuan Kuda Pacu Indonesia Mempertahankan Kecepatan Berlari. Skripsi. Institut Pertanian Bogor, Bogor.

Ardika, I.N., D.A. Warmadewi, I.G.L. Oka, N.P. Sarini, dan M. Dewantari. 2015. Bahan Ajar Ilmu Pemuliaan Ternak. Universitas Udayana, Denpasar.

Becker, W. A. 1968. Manual of Procedures in Quantitative Gentics. 2nd Ed. Washington State Universty Press, Washington

Bowling, A.T. dan A. Ruvinsky. 2000. The Genetics of the Horse. CABI Publishing. London.

Buttram, S.T., R. L. Willham, D. E. Wilson, dan J. C. Heird. 1988. Genetics of racing performance in the American Quarter Horse: I. Description of the Data. J. Anim. Sci. 66: 2791-2799. 
Corrêa, M.J.M. dan M.D.S. Mota. 2007. Genetic evaluation of performance traits in Brazilian Quarter Horse. J. Appl. Genet. 48:145-151.

Ekiz, B., dan Ö. Koçak. 2007. Estimates of genetic parameters for racing times ofThoroughbred horses. Turk. J. Vet. Anim. Sci. 31: 1-5.

Hardjosubroto, W. 1994. Aplikasi Pemuliabiakan Ternak di Lapangan. PT Grasindo. Jakarta

Langlois, B. dan C. Blouin. 2007. Annual, career or single race records for breeding value estimation in race horses. J. Livestock Science 107(2): 132-147.

Makalalag, T.T., J.H. Manopo, H.F.N. Lapian, dan U. Paputungan. 2014. Heritabilitas kecepatan lari dan tinggi badan anak kuda pacu umur 2 tahun dengan metode korelasi dalam kelas (Intraclas Corelation). J. Zootec 34(2): 89-98.

Oroh, R.K.P., J.S. Mandey, I.M. Untu, dan C.A. Rahasia. 2004. Determinasi kebutuhan energi untuk kerja berdasarkan jumlah pakan yang dikonsumsi dalam bahan kering, bobot metabolik, dan beban kerja kuda pacu. J. Zootek 25(1): 30-38.

Sabeva, I. 2000. Sources of specific variance and heritability of race time and speed in horses from thoroughbred Arabian breed. Bulg. J. Agric. Sci. 6:223-226.

Schurink, A., M.C.J. Theunissen, B.J. Ducro, P. Bijma, dan E.M. van Grevenhof. 2009. Identification of environmental factors affecting the speed of purebred Arabian racehorses in The Netherlands. Livestock Science Journal 125:97-100.
Sulastri, dan M. Hamdani. 2013. Dasar Pemuliaan Ternak. CV. Anugrah Utama Raharja. Bandar Lampung

Takaendengan, B.J., S. Adiani, dan R.R. Noor. 2011. Morphometric characterization of Minahasa Horse for breeding and conservation purposes. Media Peternakan 34(2): 99-104

Tolley, E.A., D.R. Notter, dan T. J. Marlowe. 1983. Heritability and Repitability Of Speed For 2- and 3Year-Old Standardbred Racehorses. Virginia Polytechnic Institute and State University 3, Blacksburg 24061.

Warwick, E. J. dan J. E. Legates. 1979. Breeding and Improvement of farm Animal. $\quad 7^{\text {th }}$ ed. McGraw-Hill Publishing Company Ltd, New Delhi. 